\title{
万立骏: 办好中国期刊是一项社会和科学责任
}

张学梅, 许军舰

\section{Scientific imperative and social calling: The development of top Chinese academic journals-An interview with Prof. Li-Jun Wan}

Xuemei Zhang \& Junjian Xu

doi: 10.1360/TB-2020-1214

万立骏, 中国科学院院士, 发展中国家科学院院士, 中国科学院化学研究所研究员, 中国科学院分子纳米结构 与纳米技术重点实验室主任, 中国科学院化学研究所学术 委员会主任. 曾任中国科学院化学研究所所长和中国科学 技术大学校长. 主要研究领域为电化学、能源与环境纳米 材料、扫描探针显微技术及应用. 2002年12月 2007年12月 任《科学通报》编委; 2006 2012年任《中国科学: 化学》(中 英文刊)编委, 2013年至今任该刊主编.

2020年, 在《中国科学》《科学通报》(“两刊”)迎来创 刊70周年之际, 我们专访了万立骏主编, 聆听他与 “两刊” 的故事、在带领《中国科学: 化学》中英文刊快速发展过 程中的心得体会, 以及在新形势下他对期刊未来发展的展 望与规划.

\section{回国后的第一篇文章发表在《科学通报》}

您是一位成果丰硕的科学家, 在国内外重要学术刊 物上发表论文数百篇. 您是否还记得在“两刊”发表第一 篇文章的经历?

万立骏：经历难忘！我回国后的第一篇文章就是发表 在“两刊”上. 那是 2000 年左右, 我从日本回到中国科学院 化学研究所工作后不久, 在一次学术会议上遇到了当时 《科学通报》的付利编辑, 她热情约稿, 积极鼓励我把文 章投到《科学通报》上. 是对“两刊”的崇拜, 也是被付利老 师的敬业精神感染, 我就把在日本时的一项工作整理成 稿, 投到了《科学通报》. 研究内容主要是用电化学扫描 隧道显微技术(ECSTM), 在溶液中原位研究四氰基喹啉甲 烷(TCNQ)分子在 $\mathrm{Cu}(111)$ 表面上的吸附结构. 当时这类工 作在国内还比较少见, 在国际上也属于前沿研究领域. 高 分辨的ECSTM图像可以在溶液中清晰地分辨出 $\mathrm{Cu}(111)$ 表 面TCNQ分子的每个官能团, 显示出中心苯环在 $\mathrm{Cu}(111)$ 表 面的吸附位置, 对理解表面分子成键和表面反应非常重 要. 文章以中英文对照形式发表在《科学通报》和Chinese Science Bulletin. 我在2000年“国家杰出青年科学基金”(“杰

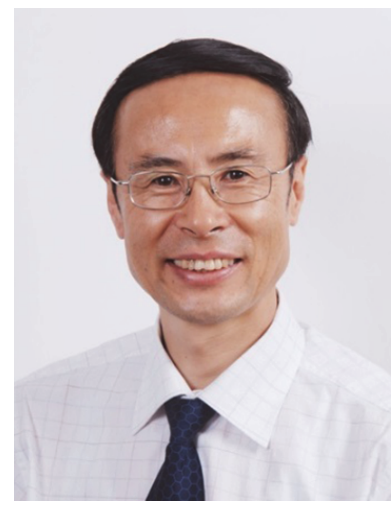

万立骏 院士

青”)的申请书中，也把这项工作做了重点介绍, “杰青”答辩 时还受到专家们的好评. 记得处理这篇稿件的也是付利编 辑, 付老师为人热情, 工作严谨、认真, 给我留下了深刻的 印象. 现在回想起来，回国后第一篇文章发表在“两刊”上, 感觉是十分荣幸与自豪的。

\section{期刊的发展得益于大家的智慧和付出}

您在2013年出任《中国科学：化学》中英文刊的主 编, 当时是怎样的背景? 您对期刊的发展是如何定位 和规划的?

万立骏: 在我担任主编之前, 《中国科学: 化学》中英 文刊主编是黎乐民院士，黎先生对期刊工作非常用心，投 人了大量精力, 使得期刊不断发展. 在黎先生做主编的第 二个任期时，我受邀成为期刊的编委. 黎先生任期结束后, 中国科学院学部推荐我来接任《中国科学: 化学》主编. 方面由于对期刊的情况有所了解，有一定的感情; 另一方 面, 也觉得我们需要有自己的优秀学术期刊, 有责任尽一 份绵薄之力, 于是我就接受推荐, 承担了这项艰巨的任务, 并决心把期刊做好.

那时候，期刊在国内科学界的影响力和吸引力都和期 
刊的地位不相称, 《中国科学: 化学》英文刊的影响因子 在1.3左右, 中文刊的发展也面临很大的稿源问题, 多数稿 件是 “人情稿件”, 是“求”我们的科学家为期刊投稿. 但是, 从国家科教发展的态势看, 我虽然压力很大, 但认为期刊 的发展一定大有前途. 只要我们群策群力, 联合国内同行, 影响国际同行, 脚踏实地提升文章质量, 提高服务质量, 期刊就一定会越办越好. 2013年申请中国科学技术学会“中 国科技期刊国际影响力计划”时, 我在答辩报告中提出, 《中国科学: 化学》应该具有这样的担当: “承担社会和科 学责任, 体现中国化学研究水平, 保护自主知识产权, 拥 有科研成果首发权”, 这应该是我们办刊初心和目标, 并 和大家一直在为之努力.

为了实现这一愿景, 您带领期刊采取了哪些主要措 施? 取得了哪些成绩?

万立骏: 首先, 非常感谢编委会团队对我工作的支持, 期刊发展一些重要举措的提出和落实都得益于大家的智 慧和付出. 我认为比较有效的措施有以下几个方面:

一是成立“青年工作委员会”. 2014年, 在副主编曹镛 先生等几位老师的倡导下, 成立了 “青年工作委员会”. 我 们按照学科方向选出了近30位年轻有为的青年学者加人, 他们活跃在科研一线, 有朝气, 这是对编委力量的补充和 加强, 也为期刊发展带来了活力, 他们不仅承担了组稿审 稿工作, 也主动为期刊投稿. 后来, 更多的青年学者也被 吸引到这支队伍当中, 大部分青年工作委员也成为新的编 委会成员.

二是改变审稿程序、增设期刊栏目. 投稿经编辑部初 篮后, 8位副主编亲自组织审稿, 严格把控并保证了发表稿 件的质量, 拒绝“关系稿”和单纯的“满足毕业要求稿”, 同 时为突破性的成果开通了 “绿色通道”. 新开辟了 Highlights、Perspectives等栏目, 设计了简明美观的目录图 (TOC)等, 增加了文章的可读性和吸引力.

三是副主编和编委率先垂范的奉献精神. 这体现在许 多方面. 比如积极贡献或组织高质量稿件, 像李永舫老师 把最好的文章投到Science China Chemistry, 多位老师带头 组织大综述等; 很多编委在学术会议上大力宣传期刊, 为 扩大期刊影响作贡献. 正是大家的身体力行加快了期刊的 发展.

四是得益于编辑部不断加强队伍建设、不断提升工作 质量和服务能力. 每位编辑都能认真了解学科发展动态和 热点, 迅速响应、落实编委们的建议, 积极主动约请稿件, 加大稿件初篮力度, 缩短出版周期, 对重要文章通过多种 形式广泛推广等, 产生了积极效果. 他们尽职、勤勉、细 致的工作是期刊进步的基础保障.

至于成绩, 我认为有两点值得一提. 一是期刊的学术 影响力有了显著的提升, 文章的质量已经不亚于一些国际 知名化学期刊, 及时报道了很多创新性强、有重要意义的
科研成果, 对化学学科的发展起到一定的推动作用, 学术 指标也在国际综合性化学期刊中排名从 Q3区进入Q1区, 2019年的期刊影响因子达到 6.356. 二是期刊的吸引力不 断增强, 目前收稿量年增长近 $50 \%$, 其中不乏有很高科学 价值的成果, 包括国外来稿. 我也时常会收到一些“慕名” 而来的投稿申请. 这与几年前相比, 有了很大改观. 这些 成绩的取得是编委会和编辑部共同努力的结果, 也得益于 科学家和读者的大力支持.

\section{办一流期刊既需要国家政策引导 又需要工匠精神}

2018 年春, 您受邀在中国科学技术协会召开的“世 界一流科技期刊建设主编座谈会”上提出, 要像建世界 一流大学一样办一批国际一流科技期刊. 这两年来, 国 家也相继出台了很多支持中国科技期刊发展的意见、措 施. 您认为这些举措是否发挥了作用? 能否谈谈您对 一流期刊的理解?

万立骏: 在那次座谈会上, 我的观点主要是办一流科 技期刊需要国家层面的政策引导和支持. 这个必要性和紧 迫性大家都知道, 关键是要有多大的决心. 很高兴看到, 在两年的时间里就有很多具体的措施落地了, 包括设立支 持一流期刊建设的项目、出台鼓励在中国期刊上发文的政 策等. 这些措施既为期刊发展提供了资金支持，也为把优 秀论文写在和留在国内期刊起到了 “引流”作用. 我相信, 有了这些保障, 一定会加快我们追赶国际先进同行的 脚步.

关于一流期刊, 很难有个定量的标准. 但我想, 一般 要具备3个要素: 一是一流的影响力, 包括发表高水准创 新成果且出版数量达到一定的规模, 能够代表一个学科的 最高水平; 二是一流的吸引力, 能够主动吸引本领域内科 学工作者的关注, 成为他们研究工作不可或缺的参考; 三 是一流的引领性, 能够引导、推动学科的发展. 所以, “一 流期刊”不是由行政命令来划定, 也不应该是单纯由影响 因子决定, 而是日积月累在科学界和科学家心中形成的口 碑和学术界的权威性.

以Science China Chemistry为例, 您认为目前我们 建设一流科技期刊的瓶颈是什么? 该如何突破?

万立骏: 客观地说, 这些年我们期刊的整体水平有了 很大提升, 与世界一流期刊的差距在逐步缩小, 甚至发表 的部分成果已经达到世界一流期刊的水平. 但我们现在发 表的文章数量还远远不够, 与化学领域公认的一流期刊 $J A C S$ (《美国化学会志》)相比, 不谈文章质量仅发文量差 距还相当大, 所以影响力, 尤其在国际上的影响力还比较 弱. 所以, 下一步在不断提高文章质量的前提下, 我们需 要逐渐扩充体量, 也就说在做强的过程中不断做大. 此外, 
缺少支撑中国科技期刊发展的技术平台也是一个重要掣 肘. 借助海外平台, 不仅使得我们的宣传和发行受限, 而 且版权没有在国内. 如果我们有自己的开放和共享的平 台, 将会有利于世界一流期刊的建设, 而且还可能吸引国 外的期刊加人. 当然这不是一本期刊能解决的问题, 需要 国家相关部门和出版机构一起努力.

现在对于中国期刊的“把脉和开方”林林总总, 我也没 有更有效的良药. 有一点体会, 我在日本生活过很多年, 非常欣赏他们的工匠精神, 做事不急功近利, 踏踏实实、

精益求精. 我认为, 办一流期刊也需要这种精神. 影响因 子只是表象, 我们更要从内涵上学习、接近世界一流期刊, 从一封退稿信的撰写、网站的页面设计等, 都需要认真思 考和不断改进. 办好一本刊是百年大计, 更是要一步一个 脚印, 行稳方能致远.

\section{行远自迩未来可期}

您担任主编期间, 期刊迎来了蒸蒸日上的发展. 有 哪些事令您印象深刻?

万立骏: 光阴荏苒, 转眼已是担任主编的第 8 个年头, 印象深刻的事情很多, 有在武汉大学樱花树下的研讨会, 也有在烟台海滨的学术报告会等. 很开心与编辑部的同志 们一起工作, 他们的青春、工作热情和激情感染了我, 受 益罒浅. 令我印象深刻的还有我们副主编、编委、青年编 委们, 他们不图名利, 为的是对发展中国化学旗舰期刊的 责任. 前些年, 我们的稿源数量不多、质量不高, 所以多靠 他们投稿、凭借个人的“人情”约稿. 即便是在困难的时候,
大家都有一个共同的意愿和付诸实际的具体行动，就是一 定要把期刊办好, 这种凝聚力和奉献精神令我深深感动. 现在期刊国际影响力显著提升，投稿量大幅增长、质量提 高, 成为真正的“学术”期刊了, 这是我们共同培育的果实, 相信大家都会欣慰和开心.

您对《中国科学: 化学》中英文刊未来的发展, 有 哪些希望?

万立骏：2013年担任主编伊始, 我提出的“承担社会和 科学责任, 体现中国化学研究水平, 保护自主知识产权, 拥有科研成果首发权”, 目前仍然是我们的办刊目标. 希 望《中国科学: 化学》成为促进国内化学学科发展和人才 培养的园地, Science China Chemistry成为在国际上具有广 泛影响力的中国化学领域旗舰期刊.

要实现这一目标, 我们还需要铸而不舍, 在竞争中努 力提升自己的实力, 正所谓“行远必自迩, 登高必自卑”. 同时, 我也希望广大的化学工作者能够一如既往地关注和 支持期刊的发展.

在“两刊”创刊70周年之际，您对“两刊”有什么寄语 和期望?

万立骏: “两刊”走过了不平凡的 70 年, 也是老一辈科 学家留给我们的宝贵财富. 我们有责任把“两刊”继续发扬 光大，以更好地服务于科技强国建设，服务于科技创新发 展. 我对“两刊”未来的发展充满信心，也期待“两刊”一路 高远, 在世界科技舞台上有一席之地, 这也是我当年选择 回国工作的初心! 